\title{
Road Traffic Accidents In Kathmandu Valley
}

Bikash Kumar Shrestha

Lecturer, Department of Geography Education,

T. U., Nepal

\begin{abstract}
This paper describes the situation of road traffic accident in Kathmandu valley for the last five years. It has focused on the causes, vehicle-types commonly involved and the trends of deaths. Based on secondary data, this study has also come up with some discussions on the preventive solution. As Road Traffic Accidents (RTAs) has been proved one of the major challenging issues of Kathmandu Valley, the concerned authority should come up with a decisive role in mitigating deaths and causalities due to this phenomenon.
\end{abstract}

Key Words: Road traffic accidents, mortality, traffic rules, injury, road traffic policy.

\section{INTRODUCTION}

Accidents are generally defined as unexpected, unplanned occurrences or events that may cause injuries or deaths. Accidents represent a major epidemic non-communicable disease in the present day world. Since the advent of vehicles, the number of road traffic accidents (RTAs) has risen proportionate to the number of vehicles manufactured. In the discourse of RTA, the term 'killed' is used for the situation in which a person who is injured in the accident dies on the spot or any time within thirty days due to that injury (WHO 1984). Reports have shown that Road traffic accidents kill about 3,000 people and 30,000 are injured disabled for life every day. This proves it as a very serious global problem in the world. In comparison to developed countries, the rate of morbidity and mortality due to RTA in developing countries is unimaginably high. Records show that developing countries account for $90 \%$ of global road traffic deaths. One of them, our country Nepal, as per the estimates of morbidity and mortality due to RTA, it contributes to $9 \%$ of total mortality.

Among the problems, the developing countries suffer from poor roads, ill-managed vehicles, and improper rush driving, highways being the sites for playground for children and inadequate teaching of traffic rules to drivers and the common people. Equally, there is inadequate incorporation of traffic rules and regulations in school curricula which has caused to increase involvement of children in RTAs. Due to the lack of effective action, the death rate caused by RTAs in low to middle-income countries forecasts to rise steeply. As highlighted in the World Report on Road Traffic Injury Prevention, fatal and long term crash injury is largely predictable, largely avoidable and a problem amenable to rational analysis and remedy. Research and experience in North America, Australia and Europe has shown that very substantial reductions in road deaths and serious injuries have been achieved through the application of evidence-based measures against the background of increased motorization. However, the case of South Asian countries is not so. WHO report shows that deaths and injury due to traffic accidents are arising dramatically. For example, every hour, 40 people in the south east-Asia Region die as a result of road traffic accidents. Deaths and injuries due to RTAs vary in terms of sex, age group and so on. Reports have shown that almost three times as many males as compared to females die out of road traffic injuries. And in terms of age groups worldwide, the mortality of 15-44 years age group is found higher than any other though the age group belonging to under 15 is not so less.

Studies related to RTAs and transportation safety has been carried out. These studies have come out with the results that the situations of road traffic accidents are much more miserable in developing countries in comparison to the developed ones (Pearce \& Maunder 1998 and 1999; Maunder et al., 2000; Jha, 2004). In their studies related to Nepal in particular and Nepal and other countries including India and others, Pearce and Maunder (1998 and 1999) have come out with several causes of road traffic accidents. Poor road structure, weak enforcement of traffic regulations and a lack of road sense by pedestrians in rural areas are among the most important factors for that.

Among the South Asian countries, RTAs in Nepal is reported even miserable. Among the major cities here, Kathmandu is considered as the city facing heavy road traffic, more accidents and more causality in terms of RTAs. So in this situation, studying the situation focusing on RTAs of Kathmandu valley is worthwhile. It is important for different reasons. Firstly, road traffic is one of the crucial problems of Kathmandu valley. Secondly, the city is facing many 
deaths every year due to road accidents. Thirdly, the number of vehicles is higher than the capacity of roads here.

\section{OBJECTIVE OF THE STUDY}

In general, the main objective of this study is to assess the situation of RTAs in Kathmandu Valley in the last five years with reference to the causes, types of vehicles commonly involved in the accidents and the trend of death. To be more specific, this study has the objectives to identify the causes of Road Traffic Accidents, to know the type of vehicles commonly involved in Road Traffic Accidents and to find out the trend of deaths due to Road Traffic in last 5 years.

\section{METHODS AND DATA}

This study is based on the secondary source of data published in the annual report of Metropolitan Traffic Office, Kathmandu. This study is limited to the study of the road accidents of only Kathmandu Valley. The 'RTAs and/or deaths' data of the last five years in terms of age, sex, causes, time frame and vehicle involved have been used and analysis has been made in the light of that. The data of the last five years have been tabulated in terms of the themes given below and analyzed using number and percentage.

\section{RTAS AND DEATHS IN TERMS OF TIME FRAME}

In terms of the time frame, RTAs and deaths are found to have quite unsystematic distribution. In the fiscal year 2066/67 (2010 A.D.), the maximum number of accidents occurred in the month of Ashad $(13.14 \%)$ and minimum in the month of Aswin (6.20\%). The fiscal year 2067/68 (2011 A.D.) records Shrawan $(12.05 \%)$ and Baisakh and Magh $(6.77 \%)$ as the maximum and minimum number of accidents respectively. Similarly, Jestha (10.34\%) and Ashad (5.15\%) are found as the months having maximum and minimum number of accidents in the fiscal year 2068/69 (2012 A.D.). Likewise, the fiscal year 2069/70 (2013 A.D.) records Jestha (10.34\%) and Ahad $(5.15 \%)$ as the months of maximum and minimum number of accidents. The distribution of deaths due to RTAs is also found heavily incoherent in these years. As its evidence, in the fiscal year 2066/67, though Ashad is the month recording maximum RTAs, Aswin (6.20\%) is found the month recording maximum death rates due to accidents.
Similarly, in the fiscal year 2067/68, Shrawan, the month having maximum RTAs, is found nearly minimum death rates $(1.79 \%)$ due to the accidents. The overall trend shows the RTAs and deaths found higher in the months of Baisakha, Jeshta, Ashad and Srawan. (MTPH, 2065/66, 2066/67; 2067/68; 2068/69; 2069/70)

The report shows that the number of RTAs is found maximum between 12:00 pm and 6:00 pm. 42.50\% accidents occur at this time. Similarly, the time between 6:00 am and 12: pm, and between 6:00 pm and 12:00 am are also found the time having significant RTAs. The former occupies $28.17 \%$ and the latter does $24.75 \%$ respectively. The time between 12:00 am and 6:00 pm is found to have less number of RTAs.

\section{RTAS AND DEATHS IN THE LAST FIVE FISCAL YEARS}

While comparing the total RTAs for the last five fiscal years, 2068/69 records the highest number of accidents $(5,069)$. Following similar rate, fiscal years 2067/68, 2069/70 and 2066/67 record 4914, 4770 and 4104 RTAs respectively. Fiscal year 2065 has the lowest number of RTAs (2765). The number of RTAs and the deaths due to that seem nearly correspondent in the last five fiscal years. Number of deaths due to RTAs records the highest in fiscal year 2067/68 and the lowest in the fiscal year 2065/66. Similarly, number of deaths of the fiscal year 2068/69 and 2069/70 is 148 each. The least number of deaths due to RTAs is 137 in the fiscal year 2065/66 (MTPH, 2065/66).

\section{THE RTAS AND DEATHS IN TERMS OF AGE AND SEX}

The distribution of RTAs and deaths in terms of age show that the age group between 21-25 years is maximally affected. It occupies $23.89 \%$ percent of the total RTAs and deaths. Following this age group, the age groups between 26-30 and 31-35 years record second (22.38\%) and third position (16.93\%) respectively. The age groups below 20 years and over 36years were found less affected in comparison to the earlier age groups. The age group over 46 years is found least affected in RTAs and deaths due to that. Regarding RTAs and deaths in terms of sex variable, in almost all fiscal years, male are found to be significantly affected than female. The fiscal year $2069 / 70$ records male deaths due to RTA comprise $81.13 \%$ whereas female comprises $14.86 \%$ only. (MTPH, 2069/70) 


\section{THE RTAS AND DEATHS IN TERMS OF CAUSES}

With reference to causes of RTAs and deaths due to that, the reports show negligence, over speed, drinking and driving, poor condition of the vehicles, overtaking as major causes. Among them, as the global trend in each of the fiscal years, 'negligence' occupies the highest position (79.03\%) of RTAs and deaths due to that. Over speed $(9.87 \%)$ is also found another serious cause of RTAs. 'Drinking and driving' is also found to have significant space in RTAs and deaths. Though less significant in comparison to the aforesaid causes, poor condition of the vehicles and overtaking are also found to have caused many RTAs and deaths.

\section{RTAS AND DEATHS IN TERMS OF VEHICLE TYPES}

In terms of the vehicle types involved in RTAs and deaths due to that, motorbike occupies the highest place. It occupies $38.80 \%$ of the total RTAs. Following this trend, car covers $30.90 \%$ of the total RTAs. Similarly, bus $(10.51 \%)$, truck $(8.43 \%)$ and microbus $(5.89 \%)$ are also found involved in many RTAs. The RTAs and deaths due to that presented above show very frightening situation of Kathmandu valley. It clearly shows that the summer season is the time in which there likely to be more accidents. Similarly, the time period between morning to noon and noon to evening are likely to have more RTAs. The people from 20 to 35 years are found more affected due to RTAs and deaths due to that. In terms of vehicle types, motorcyclists are found to be more affected. All these results imply that there should be a strong Road Traffic Policy from the side of the government. I think there should be two possible solutions to decrease the rate of RTAs and deaths caused by that. The first one is bringing change in the road infrastructure and vehicles; and second is to make the people aware of Road Traffic rules and regulations through education. The government should take a strong step to remove old vehicles, mend roads and sidewalks, zebra crossing and way maps, issuing license, training drivers and so on. It should also check the capacity of the road and the frequency and types of vehicles that can run there.
The next thing it should educate drivers and other clerks involved in transportation and common people too. It should incorporate some road traffic policy in the curricula at schools. It should equally make the traffic police much more responsible and update with Road Traffic Policy. And finally, it should strongly apply the policy of not allowing teens ride motorbike in the valley.

\section{CONCLUSION}

The finding of the study prove that Road Traffic Accident (RTAs) is really a serious problem in Kathmandu valley. Many deaths and loss of property occur due to this event every year. To lessen its effect in the valley, both the government and civil society should join hands and take some strong actions especially for improving road infrastructure, replacing old vehicles with newer ones and running awareness programs to different groups of people of the country.

\section{REFERENCES}

ADB, 1997. Road Safety Guidelines for the Asia and Pacific Region, Asian Development Bank, Manila

http:/ / metro.nepalpolice.gov.np/structure/trafficdivision.html

http:/ / traffic.nepalpolice.gov.np/

http://www.dor.gov.np/documents/RSAP_ english.pdf

Maunder D. A. C. and Pearce T., 1999. Public transport safety in Nepal and Zimbabwe. Journal of the Institution of Highways and Transportation. H. and T. Journal Vol. 46 No10 October 1999.

Maunder D. A. C. and Pearce T., 1998. Bus safety in Nepal. Indian Journal of Transport Management Vol. 22 (3).

Pearce T, Maunder D.A.C., Mbara TC, Babu DM, Rwebangira T. 2000. Bus accidents in India, Nepal, Tanzania and Zimbabwe. TRB Conference, Washington DC. 